Neil Brooks, Lyndon Simkin

Measuring marketing effectiveness: an agenda for SMEs

Marketing Review, vol. 11, no. 1 (2011)

DOI: $10.1362 / 146934711 \times 565260$

This version is available: https://radar.brookes.ac.uk/radar/items/a9005f3c-7cfb-4c70-b813-

e7caa044a447/1/

Available on RADAR: 18.11.2016

Copyright $(\odot$ and Moral Rights are retained by the author(s) and/ or other copyright owners. A copy can be downloaded for personal non-commercial research or study, without prior permission or charge. This item cannot be reproduced or quoted extensively from without first obtaining permission in writing from the copyright holder(s). The content must not be changed in any way or sold commercially in any format or medium without the formal permission of the copyright holders.

This document is the postprint version. Some differences between the published version and this version may remain and you are advised to consult the published version if you wish to cite from it. 


\title{
MEASURING MARKETING EFFECTIVENESS: AN AGENDA FOR SMES
}

Authors - Neil Brooks \& Lyndon Simkin

Affiliation - Business School, Oxford Brookes University

Contact - Neil Brooks - nbrooks@brookes.ac.uk - Wheatley Campus, Oxfordshire, OX33 $1 \mathrm{HX}, \mathrm{UK}$

\begin{abstract}
Bonoma and Clark's view (1988), that measuring marketing effectiveness is stubbornly resistant to definition and application, remains true - especially within SMEs. This article reviews many marketing effectiveness measures and concludes that none are the single 'silver bullet'. By examining how these metrics translate into practical SME usage, it asserts that many metrics do not enjoy currency, or even applicability, for small companies. This can lead to SMEs managing their marketing without adequate planning/control relying instead on anecdotes and myths. In response a practitioner agenda is proposed that assumes an incomplete measurement system is better than none and that the most pragmatic minimum start-point is segmentation, targeting and positioning and the marketing mix itself. This article provides interesting insights into the ongoing debate about measuring marketing performance.
\end{abstract}

\section{Biographies}

Neil Brooks DipM FCIM - Associate Lecturer in the Business School of Oxford Brookes University and at the Business School of Brunel University as well as running his own marketing consultancy business focused on small business in the home counties of the UK. His research interests are directed towards understanding and improving the practical application of marketing theory in a small business context. Before his involvement with Oxford Brookes University, Neil had over twenty years experience as a marketing practitioner working in senior positions with multinational organisations in the IT and high-technology sectors.

Lyndon Simkin - Professor of Strategic Marketing at Oxford Brookes University. Previously he was at Warwick Business School, where he was Director of the MSc in Marketing \& Strategy and versions of Warwick's MBA Programme. In addition to many journal articles, Lyndon has authored numerous books, including Marketing: Concepts and Strategies, Marketing Planning, Market Segmentation Success and Marketing Essentials. Lyndon is consultant to many blue chip corporations, including EDF Energy, GfK, Fujitsu, Raytheon and IKEA, plus he is a recognised High Court expert witness in cases of marketing and business planning litigation. He is also cochair of the Academy of Marketing's Special Interest Group in Market Segmentation. Lyndon has published in many journals, including the European Journal of Marketing, Industrial Marketing Management, Services Industries Journal, Journal of Marketing Management, Journal of Industrial \& Business Marketing, Journal of Strategic Marketing, OMEGA and the International Journal of Advertising.

\section{Keywords}

marketing effectiveness, marketing performance, marketing measures, marketing metrics, SME marketing, marketing practitioner, marketing mix effectiveness 


\section{MEASURING MARKETING EFFECTIVENESS: AN AGENDA FOR SMES}

\section{INTRODUCTION}

Measuring marketing effectiveness is notoriously difficult for academics and practitioners alike (Hood, 1969; Sheth and Sisodia, 1995a; Clark, 2000; Seggie et al., 2007; McDonald, 2010). This is especially the case within SMEs (Gilmore et al, 2001 Simpson et al, 2006). The academic literature of the last 40 years suggests a number of high-level reasons for why marketing effectiveness is so hard to determine for organisations of all sizes - which still exist today:

1. Marketing activity has both tangible and intangible effects. Measuring the effect of a marketing programme on a tangible element like sales volume is easy to achieve (albeit retrospectively) but assessing the effect on intangibles like brand equity can only be estimated at best (Ambler, 2003).

2. Marketing activity has both short-term and long-term (future) effects. Measuring the short-term is relatively easy, but measuring (estimating) the future is an inexact science that relies on many assumptions that are open to manipulation (Ambler, 2003). Similarly, history impacts marketing effectiveness - expenditures tend to be accounted for annually, whereas the influence of those expenditures is cumulative, thus a change in sales volume in one year could be the residual echo from previous years activity rather than current activity (Sheth et al., 2009).

3. Marketing operates within a volatile and uncontrollable external environment that includes its customers, competitors and legislators. Thus measureable effects on company performance (both positive and negative) can be experienced that are not directly attributable to the company's own marketing activities (Sheth \& Sisodia, 1995a; Rust et al., 2004a).

4. Marketing operates within an internal environment which is subject to constraint and change. Good marketing plans are informed by, and operate within, the confines of the company strategy. A poor company strategy could lead to poor marketing effectiveness through poor management rather than poor marketing (Sheth et al., 2009). Similarly, short-term executive decisions regarding marketing resources/budgets could lead to sub-optimal effectiveness. - and to make matters worse, marketers themselves may have limited skills/experience such that they "only know half of what they should about the concepts they use" (Corkindale, 2009).

5. There is corporate confusion between marketing (the total business process) and the what the marketing department does. Agreeing exactly what to measure the effectiveness of is an essential start point for any assessment process (Clark, 2000).

6. When it comes to available metrics for measuring marketing performance and/or effectiveness, marketers are spoilt for choice. In reviewing around 60 journal articles, the authors have uncovered a list of more that 250 different metrics that could wholly or partly contribute to a marketing effectiveness measure. Furthermore, in 2003, Pont and Shaw drew the conclusion that in practice the operational selection of metrics from this vast pool was more arbitrary than scientific and exhibited a clear preference for the subjective.

Clearly Bonoma and Clark's view in 1988 that "perhaps no other concept in marketing's short history has proven as stubbornly resistant to conceptualisation, definition, or application as that of marketing performance" remains true (cited in Ambler et al., 2001).

However to practice marketing without any rational means of effectiveness measurement would be reckless and wealth destroying (Ehrbar, 1999) given the amounts spent on marketing programmes. Without measurement, current programmes, new initiatives and targeted improvements cannot be validated, so even the use of imperfect measures is better than none (Sheth and Sisodia, 1995b).

But which? 
This article reviews a number of the most prominently discussed marketing effectiveness measures and highlights their principal strengths and weaknesses based on the academic literature. It loosely classifies the measures into four classes, Financial, Quantitative, Qualitative and Hybrid. Within this article, a hybrid measure is defined as an amalgam of individual measures that cross the other three classes.

The article will then discuss the differing ease of use of the highlighted measures between corporate and SME organisations (below 250 employees), before concluding with an agenda for assessing marketing effectiveness in small businesses especially where there is very limited historic or market data available.

\section{MARKETING EFFECTIVENESS MEASURES - TAKE YOUR PICK}

In his 2003 book, "Marketing and the Bottom Line" (p94), Ambler notes a five stage evolution process in the thinking of companies about marketing assessment:

1. The company is unaware of the issue of not measuring marketing effectiveness

2. Assessment is introduced but only in financial terms

3. Using financial measures alone are recognised as inadequate and a multitude of nonfinancial measures are introduced

4. The company develops market focus and the assessment measures used are streamlined to give a single coherent view of the market

5. A scientific method of assessment is adopted using a database of past and current metrics, derivatives and diagnostics to produce a shortlist of sensitive and predictive metrics.

Ambler goes on to state that companies do not always follow all five stages linearly, and indeed some can jump 'backwards' (to the third stage) with changes in senior management. A key point here is the recognition that reliance on financial measures alone is insufficient (Lehn and Makhija, 1996) occurs early in the evolution process and is therefore commonplace amongst companies today - leading to the situation where organisations are using a mix of metrics with little commonality (comparability) between them (Ehrbar, 1999).

Reports of companies with more than 100 measures in use are legendary, with Ambler (2003) quoting financial services company Skandia as having 117 at one time. He contrasts this with Diageo having a more manageable 'two dozen measures in its Brand Health Monitor' ( $p 107)$.

With the choice of metrics exceeding 250 (from the authors' research for this article), this leads to the question of which metrics, and in which combinations, should an organisation adopt?

Albert Einstein famously encapsulated the problem concisely when he said "Everything that can be counted does not necessarily count; everything that counts cannot necessarily be counted." A notion echoed by Clark (1999, p720), "The trend toward multidimensional measures has arguably been wonderful for researchers and horrible for consultants. ... unfortunately, successively more complicated schemes dramatically increase the burden on managers attempting to measure performance in the world. ... figuring out which of many measures are 'really important' may drive the conscientious manager to despair." McDonald (2010, p383) concurs when he quotes a CEO from a 2008 report by Deloittes thus, "Like other departments, Marketing always requests more budgets from me, but without the metrics in place to demonstrate the impact marketing has in financial terms to our external stakeholders."

Clearly the most appropriate metrics would seem to be those that reflect the progress, or otherwise, in fulfilling the company's stated business strategy in the context of its customers, competitors and other external factors (Clark, 2000). However these metrics may mask the true effectiveness of marketing investments. For example, in one organisation specific metrics may reflect strong work by the marketing team, but in another, the same metrics may be positively affected by the external environment despite a poor marketing strategy and/or implementation (Hood, 1969). 
However, it is often observed (somewhat cynically) that company politics and personal aspirations are the most influential in driving metric choice. According to Ambler (2003, p222), "Few companies are concerned with assessing marketing performance as a whole. Much more often, the horns are locked over the marketing budget, or some part of it." $\mathrm{He}$ goes on to add (p223), "Marketers most often use prior year for the comparative figures ... It is the weakest test because it allows the performance indicators to be selected after the event."

Even when the metrics are finally selected, there is the issue of collecting and collating data. Large companies can suffer from a confusing surplus of data whilst small companies often suffer from famine especially with regard to micro-data (Seggie et al., 2007). Similarly, to locate comparable market/competitor data can be expensive and difficult, if not impossible, in some areas.

At the same time, many popular metrics are based on customer opinions and the data collected by survey. However it is well researched that what customers say and how they subsequently behave is often very different (Sheth et al., 2009). Even specific customer satisfaction measures can generate a false impression when the customer is equally, or more, satisfied with competitive products or services (Clark, 1999).

The steady advance in computing power and software capability, along with an increasing number of internet information sources, has made the collection and analysis of many metrics much easier for many firms of varying sizes. But, according to Clancy and Stone $(2005, \mathrm{p} 28)$ this hasn't answered the marketer's prayers - "Marketers aren't unhappy because they can't measure marketing performance. They're unhappy because they now can - and they don't like what they see. ... With increasing precision, they're measuring the impact of ill-defined targeting, weak positioning, mediocre advertising, pedestrian products and services, giveaway promotions, and poorly allocated spending."

Trends in marketing effectiveness measures continue to shift, with some approaches and metrics becoming more popular and widely used and others going out of fashion. Research by Seggie et al. (2007) concluded that existent marketing metrics needed systematic reexamination and went on to formulate seven measurement themes to guide the evolution of "better measures"' (p836);

1. From non-financial to financial - greater understanding of the measure can be engendered within the organisation through using a common financial language.

2. From backward-looking to forward-looking - assessments of historic performance are poor indicators of future performance when competitive differences occur over time.

3. From short-term to long-term - many marketing activities, such as advertising, deliver long-term sales/awareness benefits that are not accrued in short-term performance measures.

4. From macro to micro data - the causes of changes in macro measures, such as a fall in market share, would not be visible without related micro data, e.g. a number of significant customers defecting to competitors.

5. From independent metrics to causal chains

- understanding the causal relationships between measureable marketing activities and profitability (or other corporate goals) will lead to improved decision making and increased predictive accuracy.

6. From absolute to relative - relative performance measures allow managers to contrast performance against competitors which is a superior indicator of actual marketing effectiveness.

7. From subjective to objective - objective measures are more trusted within organisations, especially where budget setting or employee performance dependence is involved.

Seggie et al. (2007) then ranked six popular metrics against these criteria to see if any was the single overriding metric, but none emerged in this role. 
You might like to note that their first philosophy (from non-financial to financial) is a reversal of the commonly held view that financial metrics are generally poor measures of something so complex as marketing performance. However their view is that as many organisations 'speak' financially in their common language, for marketing to opt out of this is confusing and can be seen as manipulative.

\section{MARKETING EFFECTIVENESS MEASURES - IN MORE DETAIL}

The marketing effectiveness measures that were reviewed are listed in Table 1. They have been selected based on the volume of academic discussion uncovered as well as known usage within UK companies. Unsurprisingly, given the historical antecedents of marketing performance measurement, there is a predominance of metrics that express themselves either financially or numerically.

\begin{tabular}{|c|c|c|c|}
\hline Financial & Quantitative & Qualitative & Hybrid* \\
\hline $\begin{array}{c}\text { Return On Investment } \\
\text { (Hayman and Schultz, 1999; } \\
\text { Ambler, 2003; Rust et al., 2004a; } \\
\text { D'Esopo and Almquist, 2007; } \\
\text { Ambler, 2008) }\end{array}$ & $\begin{array}{c}\text { Market Share } \\
\text { (Aaker, 1996; Clark, 2000; Ambler, } \\
\text { 2002; Ambler, 2003; Barwise and } \\
\text { Farley, 2004; Sheth et al.; 2009) }\end{array}$ & $\begin{array}{l}\text { Perceived Quality } \\
\text { (Aaker, 1996; Yoo et al., 2000; } \\
\text { Netemeyer et al., 2004; Rust et al., } \\
\text { 2004b; Jayawardena, 2010) }\end{array}$ & $\begin{array}{c}\text { Brand Equity } \\
\text { (Keller, 1993 \& 2003; Clark, 1999; } \\
\text { Schultz, 2000; Yoo et al., 2000; } \\
\text { Ailawadi et al., 2003; Ambler, 2003; } \\
\text { Rust et al., 2004a; Seggie et al., } \\
\text { 2007; Oliveira-Castro et al.,, 2008; } \\
\text { Kuhn et al., 2008) }\end{array}$ \\
\hline $\begin{array}{l}\text { Discounted Cash Flow } \\
\text { (Shapiro, 1979; Diad and Rayls, } \\
\text { 2002; Ambler, 2008) }\end{array}$ & $\begin{array}{l}\text { Customer Satisfaction** } \\
\text { (Kotler, 1991; Aaker, 1996; Ittner } \\
\text { and Larcker, 1998; Clark, 1999; } \\
\text { Berger et al., 2002; Rust et al., } \\
\text { 2004b; Naumann et al., 2009; } \\
\text { Sheth, 2009) }\end{array}$ & $\begin{array}{l}\text { Customer Satisfaction** } \\
\text { (Kotler, 1991; Aaker, 1996; Ittner } \\
\text { and Larcker, 1998; Clark, 1999; } \\
\text { Berger et al., 2002; Rust et al., } \\
\text { 2004b; Naumann et al., 2009; } \\
\text { Sheth, 2009) }\end{array}$ & $\begin{array}{c}\text { Customer Equity } \\
\text { (Lemon et al., 2001; Rust et al., } \\
\text { 2004b; Bennett and Rundle-Thiele, } \\
\text { 2005; Seggie et al., 2007) }\end{array}$ \\
\hline $\begin{array}{c}\text { Brand Valuation } \\
\text { (Srivastava et al., 1998; Yoo et } \\
\text { al., 2000; Ailawadi et al., 2003; } \\
\text { Ambler, 2003;) }\end{array}$ & $\begin{array}{l}\text { Customer Loyalty } \\
\text { (Retention) } \\
\text { (Srivastava et al., 1998; Clark, } \\
\text { 1999; Rust et al., 1999; Thomas, } \\
\text { 2001; Berger, 2002; Barwise and } \\
\text { Farley, 2004; Sheth et al., 2009) }\end{array}$ & $\begin{array}{c}\text { Brand Awareness } \\
\text { (Pappu et al., 2005; Esch et al., } \\
\text { 2006; Davis et al., 2009; Wu and } \\
\text { Lo, 2009) }\end{array}$ & \\
\hline $\begin{array}{c}\text { Customer Lifetime } \\
\text { Value } \\
\text { (Jain and Singh, 2002; Bell et al., } \\
\text { 2002; Ambler, 2003; Reinartz and } \\
\text { Kuma, 2003; Rust et al.,, 2004b; } \\
\text { Schumacher, 2007) }\end{array}$ & $\begin{array}{c}\text { Price Premium (Relative } \\
\text { Price) } \\
\text { (Aaker, 1996; Ailawadi et al., 2003) }\end{array}$ & & \\
\hline $\begin{array}{l}\text { Economic Value Add } \\
\text { (Lehn and Makhija, 1996; Ehrbar, } \\
\text { 1999; Seggie et al., 2007) }\end{array}$ & & & \\
\hline
\end{tabular}

Table 1. The Reviewed Marketing Effectiveness Measures

${ }^{*}$ The Hybrid classification is for measures that are made up of multiple metrics that transcend the other categories.

As has been identified earlier, companies will almost certainly use a number of the above metrics rather than rely on a single indicator or marketing effectiveness. The selection of which metrics to use may well rely as much on the company's ability to accurately gather the data as it does on the level of insightfulness of the metric.

\section{Financial Measures}

Return On Investment (ROI) - a well understood metric that is generally defined as the financial return divided by the value of the investment, expressed as a percentage or a ratio.

Contrasting a direct financial return with the cost of achieving that return makes ROI attractive to many managers (Rust et al., 2004a), and useful when assessing a specific marketing 'investment', like an advertising campaign, provided the timeframe is extended to capture the full return (Ambler, 2003).

ROI has no comparison baseline so real returns are hard to define, e.g. D'Esopo and Almquist (2007) cite a poll with 27 ways of defining marketing 'leads'. ROI can be 
confused with returns that may have come anyway or come from other activities (Hayman and Schultz, 1999), it rewards short-termism and does not easily account for intangibles, such as improved brand perception (Ambler, 2008).

Discounted Cash Flow (DCF) - a calculation involving forecasting future profit streams then discounting them to present day values to reflect future uncertainty the more uncertain, the heavier the discount that is applied (Diad and Rayls, 2002).

DCF is popular for brand valuation and is the underlying methodology for Customer Lifetime Value calculations. The assumptions can be standardised within a company, thus performance differences arising from strategy can be isolated from external factors - a major drawback of using ROI (Ambler, 2008).

DCF is highly sensitive to timing with high early outlays and delayed peak returns (like corporate advertising) looking undesirable (Shapiro, 1979). Specialist knowledge drives the assumptions leading to possible manipulation and difficulty in distinguishing good performance from a bad original forecast. DCF allows early credit to be taken for marketing activities not yet happened (Ambler, 2008).

Brand Valuation - "Perhaps the most widely used basis for a brand-valuation approach is the 'Price-Earnings (PE) Multiple' approach used by the InterBrand Group, in which the value of brands are estimated on the basis of incremental earnings associated with brand names multiplied by a PE multiple based on brand strength and product category attractiveness" (Srivastava et al., 1998, p9).

Ultimately the 'value' of a brand is decided by a potential acquirer (Mahajan et al., 1994), but calculating it periodically and examining reasons for change can be useful. Specialist brand valuation companies believe that the process of calculation is often more important than the result (Ambler, 2003).

Most brand valuations compare future cash flows against unbranded equivalents using assumptions made upon assumptions resulting in considerable inaccuracy (Ambler, 2003). External factors, such as PE multiples, introduce additional volatility not related to controllable marketing performance (Ailawadi et al., 2003) and some brand aspects, like image, take time to develop (Yoo et al., 2000) thus may be difficult to include.

Customer Lifetime Value (CLV) - defined as the net profit or loss from a customer over the entire life of transactions with the firm (Jain and Singh, 2002).

Calculating CLV improves understanding of customers and relationships (Schumacher 2007), powerful as firms focus towards long-term customer relationships (Rust et al., 2004b). CLV models underwrite informed decision-making for customer loyalty/retention initiatives, such as identifying profitable customers and allocating spend on retaining them (Bell et al., 2002; Jain and Singh, 2002).

CLV is difficult to calculate where many individual customers exist thus groupaggregation is used, reducing granularity and insightful impact (Ambler, 2003) especially where customers have not bought for a while (Jain and Singh, 2002; Rust et al., 2004b). Different contractual relationships affects the information available (Reinartz and Kuma, 2003), small assumptive changes generate large differences in the result and the impact of individual marketing actions cannot be estimated without knowledge of specific competitor behaviour, which is hard to get (Bell et al., 2002).

Economic Value Add - defined as the difference between a firm's net operating income after taxes and its cost of capital of equity and of debt (Stewart, 1993, cited in Seggie et al., 2007). 
EVA is an accounting measure allowing marketers a common financial language with decision makers. Including the cost of capital lends objectivity to marketing proposals and supporters claim that EVA leads to better stock market performance (Lehn and Makhija, 1996).

EVA does not consider causal relationships between marketing activity and the company's overall value, nor does it permit valid competitor comparisons, nor can it distinguish between different marketing programmes for their relative contribution (Seggie et al., 2007). EVA is backward looking (Ehrbar, 1999) and takes a short-term view, focusing on tangible results without offering solutions to shortfalls.

\section{Quantitative Measures}

Market Share - the proportion of a market's total available consumption captured by the organisation during a period of time, typically expressed as a percentage of sales value or volume. To be accurate it requires a well defined 'market' (Ambler, 2002).

Market share is popular amongst large corporations (used by $79 \%$ of 697 firms researched in 2002, cited in Barwise and Farley, 2004) as it is relatively simple to calculate, demonstrates period-on-period performance changes and provides a "valid and sensitive reflection of the brand's standing with customers" (Aaker, 1996, p115). It can highlight relative price success and sound a useful alarm should sales grow but market share fall (Clark, 2000).

Different 'market' definitions generate different shares, which can be very difficult to correct (Aaker, 1996; Clark, 2000) and opens up potential abuse. Getting market data generates technical, time-related and cost issues, and commercially-available data is often aggregated across broad 'markets'. Market share does not help define remedial actions (Sheth et al., 2009), can vary positively due to external factors whilst justifying otherwise ineffective activity (Aaker, 1996), and be 'improved' by simply reducing prices with possible long-term brand reputation damage (Ambler, 2003).

Customer Satisfaction - typically measured using customer surveys, customer satisfaction is often expressed as an index figure, being the aggregation of many satisfaction dimensions, sometimes including propensity to repurchase in the future.

Higher customer satisfaction can signify improved financial performance by increasing customer loyalty, reducing price elasticity, increasing word-of-mouth referrals, reducing sales costs and increasing brand reputation (Clark, 1999; Ittner and Larcker, 1998; Rust et al., 2004b), thus is preferred to a sales volume or market share focus (Kotler, 1991). Changes over time can flag remedial actions at a granular level including focusing on the most demanding customers to raise overall satisfaction levels (Sheth, 2009).

Customer satisfaction is not linearly linked with sales volume or profitability (Berger et al., 2002) as customers might be even more satisfied with a competitor's offer (Clark, 1999) and the index does not include non-customers at all (Aaker, 1999). Naumann et al. (2009) make the point that the method by which the customer was first acquired may affect satisfaction (and loyalty) levels in time as mergers/acquisitions between companies can often result in reduced staffing levels. Ittner and Larcker (1998) cite predicting the point of diminishing returns as a significant issue and Clark (1999) notes that base data collection and interpretation can be subjectively manipulated.

Customer Loyalty (Retention) - uses a customer's actual repurchasing history and their stated intentions (via survey) to calculate a propensity for repurchasing in the future. The growing interest in this is partly due to the limitations of customer satisfaction as a predictor of future sales and profits (Clark, 1999).

Thomas (2001, p268) states, "Analysing customer retention is an important process that can enhance the customer equity of a firm." It is popular amongst large 
corporations (used by $64 \%$ of 697 firms researched in 2002, cited in Barwise and Farley, 2004) because increased loyalty reduces cash flow vulnerability and improves planning. Existing customers cost less to service than acquiring new ones, positive word-of-mouth referrals improve brand attractiveness (Clark, 1999), and modelling the consequences of 'disloyalty' allows marketers to justify the value of positive loyalty management (Srivastava et al., 1998).

Customers are highly complex with surveyed intentions and subsequent actions being very different (Sheth et al., 2009). Dowling and Uncles (cited in Berger et al., 2002) coined 'polygamous loyalty' to describe this behaviour which effectively devalues loyalty metrics as strong indicators of future sales. Firms often favour the most loyal customers, however Rust et al. (1999) suggest attending to the newest customers instead. Meanwhile, loyalty models can be subjectively manipulated and typically struggle with customers who suspend purchasing (Clark, 1999).

Price Premium (Relative Price) - the amount extra that customers are prepared to pay for a specific brand compared to others. It should cosider a set of competitors to better reflect the brand's health as a whole (Aaker, 1996).

Price premium quantifies the residual effectiveness of historic and current marketing activity (Ailawadi et al., 2003), and is considered by Aaker (1996) to the best single measure of brand equity which can also be used as a reasonable summary of brand strength - even within a crude brand valuation (price premium multiplied by unit sales).

Where suitable sales data is not available, calculations rely on survey data which can be unreliable, especially where comparisons are made between the known brand, a private label, unbranded or even hypothetical product (Ailawadi et al., 2003). Equally, the price premium potential may be calculated erroneously where distribution channels can set pricing, legal restrictions apply, or a sudden change in market structure is not measurable until after the fact (Aaker, 1996).

\section{Qualitative Measures}

Perceived Quality - is "the customer's judgment of the overall excellence, esteem, or superiority of a brand (with respect to its intended purposes) relative to alternative brand(s)" (Netemeyer et al., 2004, p210).

Perceived quality is considered a positive driver of brand usage levels, price premiums, reduced stock returns and as a surrogate variable for components of brand equity (Aaker, 1996). Perceptions are good reflectors of attitudes to the brand as a whole (Netemeyer et al., 2004) being the result of many interactions (Yoo et al., 2000) and managing for this keeps focus on a broad range of interlinking elements.

This metric can lack sensitivity - Aaker (1996) cites Crest experiencing falling market share when Arm and Hammer introduced baking soda toothpaste, yet perceived quality was unaffected. Meanwhile, there seems to be little agreement over the effect of perceived quality on customer satisfaction (Jayawardhena, 2010), frequent use of price promotions can reduce perceived quality even when actual quality is unchanged (Yoo et al., 2000) and it is heavily affected by differences between expected and delivered quality. Rust et al. (2004a) suggest that firms should strive to match customer expectations exactly as this delivers a higher long-term preference.

Customer Satisfaction - this metric has previously been reviewed but is listed here because the information sources to calculate it are heavily founded in qualitative data.

Brand Awareness - is the measure of market members to recognise/recall a brand under differing conditions, most fundamentally the brand name itself (Davis et al., 
2009). It is generally accepted as an important element of brand equity (Pappu et al., 2005).

Brand awareness and brand image are heavily intertwined (Wu and Lo, 2009) and considered to be antecedents to brand satisfaction and brand trust (Esch et al., 2006), thus monitoring and managing awareness is considered essential in many industries - applying equally to both B2B as well as B2C brands (Davis et al., 2009).

According to research by Esch et al. (2006, p103), brand knowledge (which includes brand awareness) "does not affect future intended purchases directly". They claim that familiarity with the brand alone is insufficient to improve profitability - a positive brand relationship must exist, which requires brand satisfaction and brand trust to deliver brand attachment.

\section{Hybrid Measures}

Brand Equity - variously defined as the differential value (equity) of a product or service with its brand name compared to operating without that name. It is the accumulation of marketing investments and includes consumer-oriented items (Keller, 1993) such as awareness, attitudes, image, knowledge, as well as company-oriented items such as price premium, market share, revenues and cash flows (Ailawadi et al., 2003).

Brand equity is a more complete effectiveness metric by considering historic marketing investments, storing intangibles, and negating a criticism of ROI through a positive change in brand equity quantifying the 'return' (Ambler, 2003). Its relevance is heightened by the acceptance that branding can be a firm's most valuable asset (Keller, 1993; Oliveira-Castro et al., 2008) and reacting to changes leads to consideration of competitive advantages based on non-price competition (Yoo et al., 2000). Being a 'hybrid' measure, the calculations can reveal detailed areas of strength and weakness (Rust et al., 2004a). Keller's brand equity model for B2C brands $(1993,2003)$ has been extended to include B2B brands by Kuhn et al. (2008).

Brand equity is very difficult to measure (Keller, 1993) and hard to standardise for comparison purposes. It requires the use of a number of proxies (Ambler, 2003) and Seggie et al. (2007) suggests two measurement approaches, psychological and financial, whilst other authors put forward different variations. It can be swayed by natural 'momentum' - dissipating slowly after marketing support is reduced (Clark, 1999) - and the formulae includes future customer loyalty which can be subjective, whilst converting it into a financial value is difficult (Keller, 1993, Schultz, 2000). Brand equity is essentially a product-centred concept and is increasingly being challenged by customer equity (Rust et al., 2004a).

Customer Equity - "the total of the discounted lifetime values summed over all of the firm's current and potential customers. This definition suggests that customers and customer equity are more central to many firms than brands and brand equity are." (Rust et al., 2004b, p110).

Customer equity is more naturally expressed financially thus easy to communicate (Seggie et al., 2007), and improvement initiatives become focused on customer needs and loyalty. It accommodates the future returns from historic, current and planned marketing investments (Seggie et al., 2007). It distinguishes between the three basic purchase motivators (better value, stronger brand, switching away is too costly) and as current customers provide the most reliable source for future revenues/profits they should be the centre of marketing strategy (Lemon et al., 2001).

Customer equity is difficult to calculate and in part relies on subjective CLV calculations. According to Bennett and Rundle-Thiele (2005), customer/brand loyalty rates are falling in general thus even recently made CLV assumptions could already be inaccurate. Customer equity is a difficult competitive comparator, especially when the customers buy from competitors as well (Seggie et al., 2007). The factors that 
influence customer equity - value equity, brand equity and relationship equity (Lemon et al., 2001) - require a weighting system to correlate their relative influences, which may be subjectively constructed.

\section{CORPORATE VERSUS SME - IMPLICATIONS FOR METRIC USAGE}

There is an anonymous CEO quoted in Sheth and Sisodia (1995b, p220) that felt that, "Many companies today practice 'Just In Time' manufacturing, but 'Just In Case' marketing." Clearly believing that differentiating between marketing options using reliable and well understood predictive effectiveness measures is not pragmatic in real life, this CEO saw marketers sticking to an old fashioned 'belt-n-braces' approach.

We have seen from the assessment of the selected metrics above that each has its own difficulties in measurement, and with so many to choose from it is no wonder that many marketers stay with what they know rather than battle with new metrics needing new and/or expensive data sources, analyses and interpretations. Ambler et al. $(2001, \mathrm{p} 7)$ reiterate the case that managers can be swayed by "time, financial constraints and environmental uncertainty to take a partial view of their environment." Thus they tend to select metrics that reflect that partiality - often restricting measurement to what is 'easily measured' rather than what is most 'useful to measure'. And WYMIWYG (what you measure is what you get) rules! ... companies tend to achieve what they measure (Ambler, 2003).

To quote Clark (2000, p21), "Clearly managers are capable of assessing multiple dimensions regarding performance. The question, then, is whether they are assessing the right dimensions for their business."

Marketing academics do not always help. By couching their views in complex technical terms they can easily put off practitioners from considering new measurement options - consider this description for example, "a principal components multinomial logit regression model for estimating the Markov brand-switching matrix" (Rust et al., 2004b, p123) - one that would perhaps be immediately consigned to the rapidly growing 'too difficult' pile that exists on every marketing managers desk.

These issues apply equally well to both large and smaller organisations, but there are issues that predominate in one type of organisation or the other. Data availability and quality is an obvious one, too much data in large organisations and too little in SMEs (Ambler, 2003). Similarly, the company's management's ability/readiness to handle multiple metrics could be different - "larger companies can handle more, say 20 , metrics because they have more to draw on, whereas SMEs may need only five or six." (Ambler, 2003, p108).

Specifically focusing on the situation facing SMEs (or similarly-sized independent business units of corporates), it can be seen that they may have a number of structural difficulties in managing marketing metrics that do not as readily face their corporate cousins (Gilmore et al., 2001; Simpson et al., 2006).

- Limited, intermittent or no reliable multi-year data are independently kept on marketing activity other than financial information. This includes a lack of both internal non-financial data as well as external (market) data. All too often only anecdotal data are available.

- Company revenues can be skewed by one or two large customer changes, easily 'swamping' any marketing effects in financial results. Whilst these changes could have come about due to marketing activity, they also could have occurred due to the customer's own activity or generic market conditions.

- Agreed marketing plans can be diluted by 'events' diverting management and staff focus. At the end of the measuring period (typically the financial year), it is hard to separate the actual aggregated results from what might have been achieved should the original marketing plan have been fully executed.

- A rapid start/stop mentality (often of necessity it may be said) is commonly applied to 'discretionary' spend which disrupts marketing activity and thus measurability. This is especially true the smaller the company gets as the financial reserves to support continued marketing in 'hard times' get harder and harder to allocate. 
- The firm's management may not believe that it can afford to wait 'years' to see the value of the long term effects of marketing, so the choice of marketing activities tends to favour those with more immediate (and thus tangible) effects.

- Organisational culture operates in all firms, however, in smaller organisations the culture is closely set by the long-standing owner/manager and their personal experiences/prejudices. With these restrictions in place, marketing can only be effective within the window of operations permitted (cf: Siu and Kirby, 1998).

Remaining focused on the SME situation, conclusions can be drawn about just how practical each of the researched marketing effectiveness measures are in potential usage. This leads to a very difficult situation for an SME manager when deciding how best to proceed, especially in a very small company of, say, 30 employees or less, where a lack of data, time, expertise or confidence will abound. However, just because measuring the effectiveness of marketing decisions is difficult it should not justify not doing it (Sheth and Sisodia, 1995b), no matter how small the company.

Table 2 highlights some of the practical issues observed with using the research marketing effectiveness measures within an SME. These anecdotal observations have been made by the authors in their role as practitioners over a number of years.

\section{Financial Measures}

Return on Investment (ROI)

1. No track record in forecasting the likely returns of marketing activities, therefore hard to solve the equation.

2. Often cynical view of potential returns from marketing (based on weak and inconsistent usage of marketing tools in the past), therefore little faith in the ROI calculation.

3. Short-term management thinking limits the scope of potential returns to months/single years thus unbalancing the ratio with an investment which may well have a multi-year effect on the brand equity.

\section{Brand Valuation}

1. This is considered of questionable relevance to non-niche SMEs and often dismissed as 'out of our league'.

2. The process of collecting/analysing the data is considered too onerous for the company and the result has little practical usage.

3. The technical jargon involved is misplaced in a small company and would not gain management support.

\section{Discounted Cash Flow (DCF)}

1. Considered too difficult or not considered at all.

2. Setting the risk and future assumptions may be beyond the 'comfort/experience zone' of many small company managers.

3. The internal/external data required for the assumptions does not exist (or is not consistent) and not thought valuable enough to acquire.

\section{Customer Lifetime Value (CLV)}

1. This can be a valuable metric to companies with few relatively large customers providing the base data has been collected in the past and is easily available - which typically it is not.

2. The relative CLV of customers is often seen as intuitive knowledge within the business (based on anecdote and aggregated impression - neither of which is accurate), thus there maybe no support for specifically calculating it.

3. Many small companies have 100 s or 1,000 s of customers, so to calculate CLV, even if aggregated over a number of segment groupings, may be too onerous.

\section{Economic Value Add}

1. Not that useful as the equity capital may be very low, especially in owner-managed situation where it might be negligible, thus the formula is weak.

2. Does not identify which areas of value add were from 'marketing' per se and which from other activities that the firm naturally undertakes.

3. Changes in customer buying can have a big effect on net income which can be temporary and not related to any specific marketing activity. 


\section{Market Share}

1. External market data is typically hard/expensive to collect and not terribly accurate; whilst internal data is not always kept in a useful format (especially if the company operates across different products/services into different market segments).

2. The extent/scope of the market can be difficult to define which makes it open to debate and possible data massaging. Competitive/technical innovations may explode or contract markets rapidly invalidating previous market share calculations.

3. The usefulness of market share can be limited for companies with low shares - "so we now have $0.09 \%$ of the market, up from $0.05 \%$ " - how will this change their marketing decisions? Occasionally small companies can have a large percentage of a market, but this is typically within a specific niche again, knowing the exact percentage probably will not materially affect their marketing decisions, though a negative change over time might indicate remedial activities (or a new niche!) are needed.

\section{Customer Loyalty (Retention)}

1. Financial data on customer's is readily available through the accounting system, but customer profitability is probably not calculable on customerspecific basis as activity-based-costing is not wholly (or even partially) implemented.

2. Top customers may well be personally known to the company management, as will their perceived motivation for staying loyal, Thus, assessing loyalty beyond simple historic accounting data and the management's personal relationships is typically not valued sufficiently to warrant the cost of measuring it.

3. In B2B areas, customer loyalty can 'turn down' with customer staff changes, strategy reviews and so on that are not related to the customer service received or perceived product quality. Equally, though customers can be acquired through the movement of staff from one firm to another.

\section{Customer Satisfaction}

1. In an SME organisation, the lion's share of revenue may come from a relatively few customers, so customer satisfaction processes in the firm could be heavily skewed to keeping the 'few' happy (at the expense of the many). This may benefit the company in the short term, but over time would increase the dependence on the current customer base thus increasing risk to the business in the event of a single or multiple customer loss.

2. It can be difficult to weight satisfaction results in terms of their impact on the business - should every customer vote be equal, or rank by revenue or rank by profitability? The consequence of this decision will have a large skewing effect on the satisfaction metric results.

3. Being low on a supply chain makes a small company vulnerable to poor satisfaction management by higher chain companies because the end-using customers has to be satisfied with the aggregated quality and service of all chain members not just the SME's contribution.

\section{Price Premium}

1. In B2C markets, pricing data is relatively easy to get (by looking around), but in B2B markets this might be too difficult/expensive to achieve, especially where specific project/contract discounts are often given rather than selling from 'list price'.

2. Often small companies are price followers rather than leaders, thus they do not charge a premium. However, in some markets, small companies can deliver more a personal service thus potentially justify a price premium by changing the marketing mix, so measuring the extent of this can be useful in justifying the additional service costs, but only if they can readily capture the competitive data.

3. A sudden change in market structure, such as a large low-cost entrant, could erode an SME's price premium potential without the SME having the financial might to respond protectively.

\section{Qualitative Measures}

\section{Perceived Quality}

1. Gathering the data, other than through anecdotal means, can be expensive. Even when gathered, it is quite likely be part of a larger overall satisfaction survey and not specific enough to help improve quality.

2. Companies with support/maintenance service offers can measure quality through fault analysis, but only if they have an IT system (and supportive processes) for logging faults and resolutions. However, they do not see, and thus can not measure, negative quality perceptions that are not reported as faults.

3. Small companies do not 'have the time' (or more accurately 'set aside the time') for quality circles and other improvement initiatives as part of the culture - they tend to fire-fight instead. Thus having the perceived quality data would not necessarily drive positive systemic changes.

\section{Brand Awareness}

1. Many SME's have very small market shares within large markets, thus they tend to focus to a great extent on servicing a) customers that already know them well and $b$ ) potential customers that are somehow proximal. In this situation, knowing their brand awareness percentage across the whole market would not materially affect their operational marketing choices.

2. SMEs typically would not fund the primary market research to regularly gather comparable brand awareness statistics, preferring instead to rely on anecdotal sources.

3. SME's rarely invest in the extensive and sustained advertising that might be required to drive improved brand awareness in their target markets, thus measuring brand awareness with no reliable means of changing it would be futile. 
Customer Satisfaction

Already covered above.

Hybrid Measures

Brand Equity

1. Calculating brand equity would be thought of as too expensive and too difficult. Collecting and collating the volume of data needed as well as defining the calculation weightings are considered beyond the day-to-day competence of marketing staff.

2. SMEs typically do not give as much consideration to their brand, its attributes and values, as do larger organisations - thus they might not see brand equity calculations as relevant/valuable

3. Small companies could find it hard to make specific decisions (within their budget and resource constraints) to manage for brand equity rather than enacting short-term marketing campaigns designed to raise immediate revenues. A rise in brand equity may well be considered merely a beneficial byproduct of a revenue-focused activity as opposed to a goal in itself.

\section{Customer Equity}

1. Within SMEs this would typically be thought of as too difficult to calculate. Setting the future assumptions may be beyond the 'comfort/experience zone' of many small company managers.

2. Relatively small changes in customer spending can represent major swings in CLV for a small firm these can not be predicted or easily attributed to specific marketing activity and could be more affected by general market conditions instead.

3. Whilst customer equity calculations do give strong indications of future revenue streams they assume a level of repeat purchasing and customer churn. SMEs are highly vulnerable to the impact of customer sabbaticals or defections, thus higher risk factors are needed which would lead to a reduced attractiveness for proposed marketing initiatives.

Table 2. Practical Issues With Marketing Metrics Within SMEs

As can be seen from Table 2, very small companies in particular often find it more efficient to adopt a more pragmatic approach to measuring marketing decisions and the effectiveness of previous activity because sophisticated data gathering and analysis is relatively difficult and expensive. Given that marketing is almost always a better strategy than merely selling because it builds for the future as distinct from existing hand-to-mouth (Ambler, 2003), a method of systemising a pragmatic way of judging historic, current and future marketing effectiveness is needed that applies to very small companies.

A key requirement here, from the practitioner research conducted by this article's authors, is to work within the available data and company culture to develop a locally understood and accepted 'scoring' system for historic marketing effectiveness. The two gating factors of data and company culture need to be well understood on a company by company basis, however some generalisations can be drawn in advance.

In terms of available data, smaller companies tend to keep less non-financial data than larger companies and very often rely heavily on their innate 'knowledge' of their customers, competitors and market in general to make marketing decisions. There is a general lack of objective data relating marketing activity to business performance (Simpson et al., 2006).

As a marketing practitioner operating in this field the lack of accurate or time-series data can be very frustrating. Yet planning future marketing activity with no recognition of past successes or failures is not acceptable. Thus the practitioner has to make use of what is available - and that is typically qualitative data, often of an anecdotal nature, combined with observational data analysed within the context of perceived industry norms.

Regarding company culture as a gating factor, marketing decisions in very small firms are often driven by the lack of specialist marketing expertise and the specific way that the ownermanager runs their business - a condition referred to by Welsh and White (1981) as resource poverty. According to Gilmore et al., $(2001$, p6) the result is that, "SME marketing is likely to be haphazard, informal, loose, unstructured, spontaneous, reactive, built upon and conforming to industry norms."

Taken to extreme, whole avenues of marketing options may be defined as 'no go' areas within a small company entirely due to the owner-manager's prejudice. In one practitioner example, a firm of solicitors refused to consider telemarketing as an option for generating new commercial clients as it was considered 'unseemly' in that profession. This despite the reality of many competitors using that tool effectively in the legal services market. 
Whilst some sympathy must accrue to the owner-manager as to be successful they must exhibit a broad range of skills and knowledge to constantly deal with and solve problems that impact every aspects of their business operations (Giroux, 2009), in this 'jack of all trades, master of none' context, it can be difficult to 'prove' the effectiveness of certain marketing approaches that might be recommended for the future, except through reference to industry norms or specific competitor case studies - should they exist.

Thus the task for the marketing practitioner is to assess historic marketing effectiveness from what information exists, often limited to financial and some anecdotally-based qualitative data, in the context of the company/managerial culture and come up with recommendations for the future that will match the financial (and hopefully some defined non-financial) goals of the business.

\section{CONCLUSION - AN AGENDA FOR SMES}

Despite being difficult, we know that failing to measure the effectiveness of previous, current and planned marketing activity is unacceptable (Sheth and Sisodia, 1995b). Yet practitioners working with SMEs must find a pragmatic way to navigate the haphazardness, data poverty and cultural restrictions that they meet 'on the ground' (Welsh and White, 1981; Gilmore et al., 2001). With that in mind the authors offer this agenda for consideration when working with SMEs.

1. Work within whatever historic information the company has (financial, anecdotal, ...) but authenticate elements with customer/partner surveys and competitor reviews where possible.

2. Consider as many aspects of the full marketing process as are reasonably practical within the confines of the SME's current situation. As a minimum this might need to be restricted to Segmentation, Targeting and Position and the marketing mix alone, especially when the company culture does not consider anything other than promotion to be 'marketing' (Siu and Kirby 1998). Broader elements of the marketing process can be considered in future iterations after the SME has 'learnt' to capture relevant information and understand the motives and implications of such.

3. Create a jargon-free method of communication that the practitioner and company can use to rationally discuss/decide on marketing matters.

4. Use visual indicators to deliver a marketing effectiveness measure (or maybe just a marketing mix effectiveness indicator) that the company can understand and accord with. This indicator will most likely be an aggregate of a number of marketing measurement metrics, the constituents of which may not need to be exposed to the company management.

5. Create an agreed activity plan for the marketing areas that will improve future effectiveness along with easily understood measurement criteria to measure that improvement.

6. Try to create a company culture that readily captures and retains base data that is useful to future marketing effectiveness measurement.

Whilst it seems that Bonoma and Clark's view (1988), that measuring marketing effectiveness is stubbornly resistant to definition and application, remains true especially within SMEs - with the above agenda things could be significantly improved whilst still reflecting the working behaviours, constraints, priorities and scale of most SME leaderships. 


\section{REFERENCES}

Aaker, D.A. (1996), "Measuring brand equity across products and markets”, California Management Review, Vol. 38, pp. 102120.

Ailawadi, K. L., Neslin, S. A., and Lehmann, D. R. (2003), "Revenue premium as an outcome measure of brand equity", Journal of Marketing, Vol. 67 No. 4, pp.1-17.

Ambler, T. (2008) "Marketing Metrics", Chapter 21, in Baker, M and Hart, S. (ed.), The Marketing Book (Sixth Edition), Oxford: Butterworth-Heinemann, pp. 414-427.

Ambler, T. (2003), Marketing and the Bottom Line, 2nd ed., London: FT Prentice-Hall.

Ambler, T. (2002), "Marketing metrics: what should we tell the shareholders", Balance Sheet, Vol. 10 No. 1, pp. 47-50.

Ambler, T., Kokkinaki, F., Puntoni, S. and Riley, D. (2001), "Assessing Market Performance: The Current State of Metrics", Centre for Marketing Working Paper No. 01-903.

Barwise, P. and Farley, J. (2004) "Marketing metrics: status of six metrics in five countries", European Management Journal, Vol. 22 No. 3, pp. 257-262.

Bell, D., Deighton, J., Reinartz, W., Rust, R. and Swartz, G. (2002), "Seven barriers to customer equity management", Journal of Service Research, Vol. 5 No. 1, pp. 77-85.

Bennett, R. and Rundle-Thiele, S. (2005), "The brand loyalty life cycle: implications for marketers", Journal of Brand Management, Vol. 12 No. 4, pp. 250-263.

Berger, P., Bolton, R., Bowman, D., Briggs, E., Kumar, V., Parasuraman, A. and Terry, C. (2002), "Marketing actions and the value of customer assets: a framework for customer asset management", Journal of Service Research, Vol. 5 No. 1, pp. 39-54.

Bonoma, T. V. and Clark, B. C. (1988), Marketing Performance Assessment, Boston: Harvard Business School Press.

Clancy, K. J. and Stone, R. L. (2005), "Don't blame the metrics”, Harvard Business Review, Vol. 83 No. 6, pp. 26-28.

Clark, B. H. (1999), "Marketing performance measures: history and interrelationships", Journal of Marketing Management, Vol. 15 No. 8, pp. 711-732.

Clark, B. H. (2000), "A summary of thinking on measuring the value of marketing", Journal of Targeting, Measurement and Analysis for Marketing, Vol. 9 No. 4, pp. 357-369.

Corkindale, D. (2009), "Are marketers only half right?”, The Marketing Review, Vol. 9 No. 1, pp. 19-29.

Davis, D., Golicic, S. and Marquardt, A. (2009), "Measuring brand equity for logistics services", The International Journal of Logistics Management, Vol. 20 No. 2, pp. 201-212.

D'Esopo, M. and Almquist, E. (2007), "An approach to mastering the marketing mix", Business Strategy Series, Vol. 8 No. 2 , pp. 122-131.

Diad, S. and Ryals, L. (2002), "Options theory and options thinking in valuing returns on brand investments and brand extensions", Journal of Product and Brand Management, Vol. 11 No. 2, pp. 115.

Ehrbar, A. (1999), “Using EVA to measure performance and assess strategy”, Strategy and Leadership, Vol. 27 No. 3, pp. 20

Esch, F., Langer,T., Schmitt, B. and Geus, P. (2006), "Are brands forever? How brand knowledge and relationships affect current and future purchases", Journal of Product and Brand Management, Vol. 15 No. 2, pp. 98-105.

Gilmore, A., Carson, D. and Grant, K. (2001), "SME marketing in practice", Marketing Intelligence \& Planning, Vol. 19 No. 1, pp. 6-11.

Giroux, I. (2009), "Problem solving in small firms: an interpretive study", Journal of Small Business and Enterprise Development, Vol. 16 No. 1, pp. 167-184.

Graham, C. D. A. (2009), "What's the point of Marketing anyway? The prevalence, temporal extent and implications of longterm market share equilibrium", Journal of Marketing Management, Vol. 25 No. 9-10, pp. 867-874.

Hayman, D. and Schultz, D (1999), "Measuring returns on marketing and communications investments 2000", Strategy and Leadership, Vol. 27 No. 2, pp.26-32.

Hood, N. (1969), "A conceptual framework for the measurement of marketing efficiency", European Journal of Marketing, Vol. 3 No. 1, pp. 13-17.

Ittner, C. D. and Larcker, D. F. (1998), "Are non-financial measures leading indicators of financial performance? An analysis of customer satisfaction", Journal of Accounting Research, Vol. 36(supplement), pp.1-35.

Jain, D. and Singh, S. S. (2002), "Customer lifetime value research in marketing: a review and future directions", Journal of Interactive Marketing, Vol. 16 No. 2, pp. 34-46.

Jayawardhena, C. (2010), "The impact of service encounter quality in service evaluation: evidence from a business-business context", Journal of Business \& Industrial Marketing, Vol. 25 No. 5, pp. 338-348.

Keller, K.L. (1993), "Conceptualizing, measuring, and managing customer-based brand equity", Journal of Marketing, Vol. $\mathbf{5 7}$ No. 1, pp. 1-22.

Keller, K.L. (2003), Strategic Brand Management: Building, measuring and Managing Brand Equity, $2^{\text {nd }}$ ed., Englewood Cliffs: Prentice-Hall. 
Kotler, P. (1991), Marketing Management, $7^{\text {th }}$ Edition, Englewood Cliffs: Prentice Hall.

Kuhn, K-A., Alpert, F. and Pope, N. (2008), "An application of Keller's brand equity model in a B2b context", Qualitative Market Research: An International Journal, Vol. 11 No. 1, pp. 40-58.

Lehn, K. and Makhija, A. (1996), "EVA and MVA as performance measures and signals for strategic change", Strategy and Leadership, Vol. 24 No. 3, pp. 34.

Lemon, K. N., Rust, R. T. and Zeithaml, V. A. (2001), "What drives customer equity?”, Marketing Management, Vol. 10 No. 1 , pp. 20-25.

Mahajan, V., Rao, R. and Srivastava, R. (1994), "An approach to assess the importance of brand equity in acquisition decisions," Journal of Product Innovation Management, Vol. 11 No. 3, pp. 221-235.

McDonald, M. (2010), "A brief review of marketing accountability, and a research agenda", Journal of Business \& Industrial Marketing, Vol. 25 No. 5, pp. 383-394.

Naumann, E., Williams, P., Sajid Khan, M. (2009), "Customer satisfaction and loyalty in B2B services: directions for future research", The Marketing Review, Vol. 9 No. 4, pp. 319-333.

Netemeyer, R.G., Krishnan, B., Pullig, C., Wang, G., Yagci, M., Dean, D., Ricks, J., and Wirth, F. (2004), "Developing and validating measures of facets of consumer-based brand equity", Journal of Business Research, Vol. 57, pp. 209-224.

Oliveira-Castro, J.M., Foxall, G.R., James, V.K., Pohl, R., Dias, M.B. and Chang, S.W. (2008), "Consumer-based brand equity and brand performance", The Service Industries Journal, Vol. 28 No. 4, pp. 445 - 461.

Pappu, R., Quester, P. and Cooksey, R. (2005), "Consumer-based brand equity: improving the measurement - empirical evidence", Journal of Products and Brand Management, Vol. 14 No. 3, pp. 143-154.

Pont, M. \& Shaw, R. (2003), "Measuring marketing performance: a critique of empirical literature", ANZMAC 2003 Conference Proceedings, Adelaide 1-3 December 2003, pp. 2064-2073.

Reinartz, W. and Kuma, V. (2003), "The impact of customer relationship characteristics on profitable lifetime duration”, Journal of Marketing, Vol. 67 No. 1, pp. 77-99.

Rust, R. T., Ambler, T., Carpenter, G. S., Kumar, V. and Srivastava, R. K. (2004a), "Measuring marketing productivity: current knowledge and future directions",. Journal of Marketing, Vol. 68 No. 4, pp. 76-89.

Rust, R. T., Lemon, K. N. and Zeithaml, V. A. (2004b), "Return on marketing: using customer equity to focus marketing strategy", Journal of Marketing, Vol. 68 No. 1, pp. 109-127.

Rust, T., Inman, J., Jia, J. and Zahorik, A. (1999), "What you don't know about customer-perceived quality: the role of customer expectation distributions", Marketing Science, Vol. 18 No. 1, pp. 77-92.

Schultz, D. E. (2000), “Understanding and measuring brand equity”, Marketing Management, Vol. 9 No. 1, pp. 8-9.

Schumacher, N. (2007), "Measuring customer lifetime: white paper”, American Marketing Association, Chicago.

Seggie, S., Cavusgil, E. and Phelan, S. (2007), "Measurement of return on marketing investment: a conceptual framework and the future of marketing metrics", Industrial Marketing Management, Vol. 36 No. 6, pp. 834-841.

Shapiro, J. (1979), "Taking the chance out of choice”, Strategy and Leadership, Vol. 7 No. 3, pp. 9.

Sheth, J. (2009), "Beyond customer satisfaction: how to retain satisfied customers", retrieved from http://www.jagsheth.net on 27/05/2009, pp. $1-16$.

Sheth, J. and Sisodia, R. (1995a), "Feeling the heat - part 1", Marketing Management, Vol. 4 No. 2, pp. 9-23.

Sheth, J. and Sisodia, R. (1995b), "Improving marketing productivity", in Jeffrey Heilbrunn (ed.), Marketing Encyclopaedia, NTC Books, pp. 217-237.

Sheth, J., Sisodia, R. and Sharma, A. (2009), "The challenges of improving marketing productivity and performance", retrieved from http://www.jagsheth.net on 27/05/2009, pp. 1-35.

Simpson, M., Padmore, J., Taylor, N. and Frecknall-Hughes, J. (2006), "Marketing in small and medium sized enterprises", International Journal of Entrepreneurial Behaviour \& Research, Vol. 12 No. 6, pp. 361-387.

Siu, W. and Kirby, D.A. (1998), "Approaches to small firm marketing: a critique", European Journal of Marketing, Vol. 32 No. 1/2, pp. 40-60.

Srivastava, R. K., Shervani, T. A. and Fahey, L. (1998), "Market-based assets and shareholder value: a framework for analysis", Journal of Marketing, Vol. 62 No. 1, pp.2-18.

Thomas, J.S. (2001), "A methodology for linking customer acquisition to customer retention", Journal of Marketing Research, Vol. 38, pp. 262-268.

Welsh, J. and White, J. (1981), "A small business is not a little big business", Harvard Business Review, Vol. 2 No. 12, pp. 2-12.

$\mathrm{Wu}, \mathrm{S}$. and Lo, C. (2009), "The influence of core-brand attitude and consumer perception on purchase intention towards extended product", Asia Pacific Journal of Marketing and Logistics, Vol. 21 No. 1, pp. 174-194.

Yoo, B., Donthu, N. and Lee S. (2000), "An examination of selected marketing mix elements and brand equity", Journal of the Academy of Marketing Science, Vol. 28 No. 2, pp. 195-211. 